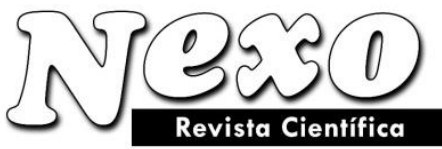

Vol. 31, No. 02, pp. 89-103/Diciembre 2018
ISSN-E 1995-9516

Universidad Nacional de Ingeniería COPYRIGHT @ (UNI). TODOS LOS DERECHOS RESERVADOS http://revistas.uni.edu.ni/index.php/Nexo http://dx.doi.org/10.5377/nexo.v31i2.6833

\title{
LA BIOPROSPECCIÓN EN NICARAGUA: AVANCES EN LA BÚSQUEDA DE APLICACIONES AGRÍCOLAS, INDUSTRIALES Y AMBIENTALES
}

\section{BIOPROSPECTING IN NICARAGUA: ADVANCES IN SEARCH OF AGRICULTURAL, INDUSTRIAL AND ENVIRONMENTAL APPLICATIONS}

\author{
L.A. Páramo-Aguilera ${ }^{1 *}$, E.J. Fonseca-Cruz ${ }^{2}$, H.D. Delgado-Silva ${ }^{2}$, K.E. Cabistán-calderón ${ }^{2}$, C.K. \\ Ríos-Guevara ${ }^{2}$. \\ ${ }^{1}$ Universidad Nacional de Ingeniería. Programa de Investigación, Estudios Nacionales y Servicios del \\ Ambiente (PIENSA). Managua, Nicaragua. \\ *leandro.paramo@piensa.uni.edu.ni; lparamo2014@gmail.com \\ ${ }^{2}$ Universidad Nacional de Ingeniería. Facultad de Ingeniería Química. erickfonseca16@gmail.com ; \\ dodanig94@yahoo.es; cabistank@gmail.com; ckrios92@gmail.com
}

(recibido/received: 22-Agosto-2018; aceptado/accepted: 21-Octubre-2018)

\section{RESUMEN}

Nicaragua pertenece a uno de los bloques de mega diversidad del mundo. Se considera que por ser un puente geográfico posee una posición tropical privilegiada que se traduce en más de 20 diferentes ecosistemas ricos en biodiversidad. Por Bioprospección entendemos la investigación realizada para identificar especies, variedades, genes y productos con usos actuales o potenciales por parte de la humanidad. Los trabajos de Bioprospección reportados por medio de estos avances, han permitido que la fecha se cuente con 92 aislados de la quesera artesanal Pedro lazo (76 bacterias, 3 hongos levaduriformes y 13 aislados de hongos filamentosos). Un total de 68 aislados de las minas artesanales de La Libertad, Chontales (44 aislados bacterianos, 6 hongos levaduriformes y 18 aislados de hogos filamentosos). De la reserva ecológica El Chocoyero / El Brujo, se obtuvieron 44 aislados puros (22 son bacterias y los otros 22 son hongos filamentosos). Finalmente; Del Río Chiquito en la ciudad de León, se obtuvo 51 aislados puros (43 son aislados bacterianos, 7 son hongos filamentosos y 1 es un hongo levaduriforme). Para un gran total de: 255 aislados entre bacterias, hongos filamentosos y levaduriformes, entre los cuales se espera encontrar muchos con enormes potencialidades biotecnológicas.

Palabras claves: Bioprospección; Aislar; Purificar; Identificación microbiana; Potencial biotecnológico.

\section{ABSTRACT}

Nicaragua belongs to one of the mega diversity blocs of the world. Since it is considering to be a geographic bridge, it possesses a privileged tropical position that translates into more than 20 different rich ecosystems in biodiversity. Due to bio-prospecting we understand the research in order to identify species, variety, genes and products with potential or actuals current uses for the human beings. The bio-prospecting advances reported in this article, has permitted until to date, to obtain 92 isolated forms in the Pedro Lazo cheese handcrafted company (76 bacterial, 3 yeast fungus type and 13 isolate filamentous fungus type). A total of 


\section{L.A. Páramo-Aguilera et al.}

68 isolate in the handcrafted mine from la Libertad, Chontales (44 isolated bacterial, 6 yeast fungus type and 18 isolated filamentous funguses type). From the ecological reserve, El Chocoyero / El Brujo, 44 pure isolated were obtained ( 22 bacterial and 22 filamentous fungus). Finally; from Rio Chiquito in Leon city, 51 pure isolated were obtained (43 isolated bacterial, 7 filamentous fungi and 1 yeast fungi type). In summary: 255 isolate were obtained between bacterial, filamentous fungus and fungi yeast type, in which we expect to find many isolated with enormous biotechnological potentials.

Keywords: Bioprospecting; To isolate; To purify, Microbial identification, Biotechnological potentials.

\section{INTRODUCCIÓN}

La bioprospección relacionada a la biodiversidad se entiende como la búsqueda sistemática de genes, componentes naturales y organismos completos en la naturaleza, buscando darles un potencial para el desarrollo de productos. En cuanto a bioprospección en Centroamérica, el ejemplo del que más se habla es la experiencia del INBio, Instituto Nacional de Biodiversidad, de Costa Rica, que además de ingresos, ha dejado una enorme experiencia de investigación y conocimiento sobre la biodiversidad del país. La bioprospección resulta útil para descubrir, conocer, cultivar, manejar y aprovechar plantas, animales y microorganismos obteniendo productos de calidad. También es útil para saber cómo manejar de manera óptima los recursos que ya se conocen y cómo darles nuevos usos, sin agotarlos. Involucra tres etapas o ejes: investigar, transformar en producto y comercializar (Huete-Pérez, 2008). A nivel internacional se maneja primordialmente la bioprospección relacionada con metabolitos secundarios, debido al impacto económico generado por la industria farmacéutica. Sin embargo, es una concepción restrictiva que excluye la búsqueda de genomas y componentes biológicos primarios como alimentos y fibras, protección de cultivos mediante la aplicación de insumos biológicos, biotecnología entre otros de importancia económica y que también son industrias de la bioprospección que aprovechan la diversidad biológica. La bioprospección también implica desarrollar el conocimiento y los procesos tecnológicos necesarios para obtener la materia prima en cantidad suficiente, lo cual impide el extractivismo que históricamente ha agotado buena parte de los recursos naturales de la humanidad (Hazen et al., 2013). La bioprospección se perfila como un proceso que involucra tres etapas o ejes: investigar, transformar en producto y comercializar. Para avanzar en dicho proceso en el país se requiere preferiblemente del trabajo conjunto de los sectores académico, empresarial nacional o internacional, comunitario y gubernamental, además de establecer claramente qué se quiere hacer y para dónde se va (Melgarejo, 2003).

Según investigaciones realizadas en diferentes países Latinoamericanos, la Bioprospección microbiana ha resultado beneficiosa en la búsqueda de solución a problemas medio ambientales, así como una fuente de ingresos económicos (biorrecuperación de suelos, biosaneamiento de efluentes, enzimas de restricción y microorganismos usados como fijadores de nitrógeno), (Bonilla, 2013). Martínez-Alonso \& Gaju (2005), realizaron estudios en estratos inferiores donde se encontraron bacterias fototróficas anaerobias a las cuales se le sugirieron aplicaciones en las prácticas de biorrecuperación, muy particularmente en aquellos afectados por los derrames de petróleo. También, Lezama-Cervantes et al., (2010), plantearon la utilización de tapetes microbianos en el biosaneamiento de los efluentes del cultivo de camarón (Litopenaeus vannamei), en una granja mexicana para disminuir el impacto ambiental producido por la generación de subproductos derivados de esta actividad. Por otra parte, en el estudio de Peña \& Reyes (2007), se logró el aislamiento de bacterias rizosféricas y endófitas de las semillas de lechuga (Lactuca sativa L.), para evaluar su potencial como fijadoras de nitrógeno.

A pesar de diversas dificultades - como la falta de una masa crítica mínima, carencia de inversión y poco involucramiento del sector productivo local- aun países pequeños como Nicaragua presentan formidables oportunidades para el desarrollo endógeno de la biotecnología. No debería pasar desapercibido el hecho de que las tres cuartas partes del total de publicaciones de investigadores nicaragüenses registradas en bases de datos internacionales están dedicadas a salud y medioambiente (disciplinas de las ciencias naturales). De

Nexo Revista Científica / Vol. 31, No. 02, pp. 89-103 / Diciembre 2018 


\section{L.A. Páramo-Aguilera et al.}

modo que las capacidades existentes en investigación biomédica, como microbiología, bioquímica, biodiversidad, epidemiología y más recientemente en biología molecular, junto al boom experimentado en las tecnologías de la información, representan una oportunidad, una base sólida sobre la cual se pueden organizar programas integrales de investigación y desarrollo biotecnológico (Huete-Pérez, 2008). La universidad Nacional de Ingeniería (UNI) de Managua, Nicaragua ha venido realizando inversiones en aras de fortalecer un laboratorio de biotecnología que le permita impulsar un proyecto nacional de bioprospección, desde la óptica de convencer haciendo. Es bien sabido que en Nicaragua existe una muy pobre inversión en materia de investigación científica, una visión empresarial privada y pública carente del conocimiento sobre la importancia y los valiosos réditos que podrían obtenerse de un programa de inversión sostenida en investigación, por tanto; el presente trabajo pretende despertar el interés por la investigación en un aspecto vital como lo es la bioprospección de nuestra biodiversas microbiana y de esta forma incentivar el desarrollo productivo de nuestro país en biotecnología.

\section{MATERIALES Y MÉTODOS}

\subsection{Ubicación del estudio}

Ante el escenario de una abundante riqueza biológica en Nicaragua se definió ubicar este estudio en lugares como el municipio de La Libertad departamento de Chontales (Aquí fue muestreada una Quesera y una minera artesanal), por presentar condiciones medioambientales favorables para la producción, hecho que le confiere ser un territorio donde se desarrollan diversas actividades económicas como la ganadería, agricultura, minería, etc. Otros sitios como la reserva natural "El chocoyero-El brujo" ubicado en el municipio de Ticuantepe, lugar poco intervenido por el hombre y por ende con una gran riqueza biológica, así como en el rio chiquito ubicado en el municipio de León en donde se observa una elevada contaminación debido a la industria y a las viviendas aledañas al rio.

\subsection{Recolección de muestras e inoculación de medios seleccionados}

Los muestreos se realizaron en forma aséptica utilizando técnicas no invasivas. Se tomaron muestras por duplicado en cada punto con hisopos esterilizados para inocular en medios solidos preparados en placas Petri previamente definidos (Medio Agar nutritivo (AN), medio Agar Papa y Dextrosa (PDA), Medio Luria Bertani (LB) y Medio Plate Count Agar (PCA), Agar Leche (AM)) en los cuales se logró el crecimiento de un amplio espectro de microorganismos cultivables presentes en los lugares de muestreo. Según el lugar muestreado (Quesera y mineras artesanales, Reserva natural y Rio Chiquito), se definieron diferentes puntos de muestreo en cada lugar, tratando de abarcar el mayor número de condiciones observables en el lugar y que permitiese la mayor captura microbiana posible (Páramo-Aguilera, 2011).

\subsection{Selección, purificación e identificación de cultivos aislados}

Una vez inoculadas las muestras en los medios de cultivo estas fueron trasladadas lo más rápidamente posible al laboratorio, cuidando de que las placas fueran bien cerradas para evitar cualquier contaminación ambiental. Luego en el laboratorio se procedió a incubar las muestras tomadas en placas Petri de medios sólidos en un rango de temperaturas entre 28 y 30 grados Celsius, que es la temperatura a la que crecen microorganismos mesófilos. Diariamente se revisaron las placas para determinar el momento de retirarlas de la incubadora en función del crecimiento observado y del tipo de microorganismos identificados desde el punto de vista morfológico. Una vez concluida la etapa anterior, se procedió al aislamiento de cada especie observada según su morfología en el crecimiento de las placas, hasta determinar que se contaba con cultivos puros, tomando en cuenta si se trataba de un hongo levaduriforme, de un hongo filamentoso o de una bacteria como resultado de su observación al microscopio. Finalmente se realizó la identificación preliminar de cada microorganismo por vía morfológica, utilizando las siguientes técnicas microbiológicas: gota aplastada, 


\section{L.A. Páramo-Aguilera et al.}

tinción simple, tinción Gram y observación de esporas de hongos filamentosos (Páramo-Aguilera, 2011., Páramo-Aguilera, 2012a; Páramo-Aguilera, et al., 2012b).

\section{RESULTADOS Y DISCUSIÓN}

Cuando se habla de bioprospección se pone de presente una investigación científica aplicada, que tiene por objeto la búsqueda, con fines comerciales, de los componentes naturales valiosos de los organismos. Consiste en descubrir componentes de aplicación potencial en los sectores alimentario, industrial y farmacéutico, entre otros (Galeano, 2009). Conscientes de la importancia de la biotecnología para el crecimiento económico, no solamente los países desarrollados como Estados Unidos, Japón y muchos países europeos han decidido invertir en este sector, sino también países en vías de desarrollo como Argentina, Chile, México y Brasil. Brasil, que viene invirtiendo millones de dólares en los últimos años, implementa desde 2007 nuevas políticas, incentivos y programas con los que aspira a convertirse en uno de los primeros cinco polos mundiales, esperando inversiones anuales de cerca de 500-1,000 millones de dólares.

Nicaragua, ha comenzado a dar pasos en el sentido de invertir en biotecnología y los resultados que se mostrarán son parte de un esfuerzo comenzado de manera puntual por muchos desde hace varios años en materia de bioprospección y que en la práctica se requiere de mayores esfuerzos para lograr llevar a la aplicación, puesta en marcha y que retribuya a los sectores más necesitados. Este proyecto, es un esfuerzo en ese sentido, buscando microrganismos útiles desde el punto de vista biotecnológicos en sectores seleccionados del país y que permita el desarrollo de procesos que impacten en la agricultura, la industria y el medio ambiente.

\subsection{Muestreo a una Microempresa quesera (Pedro Lazo) en la Libertad Chontales.}

Las actividades de Bioprospección, pueden teóricamente contribuir al desarrollo sostenible proveyendo incentivos para la conservación, mientras se desarrollan capacidades tecnológicas que aumenten a largo plazo las oportunidades para un crecimiento económico. El problema es cómo transformar este potencial teórico en una realidad. El municipio de la Libertad Chontales refleja 1,966 viviendas con 1,131 distribuidas en 25 Comarcas y 835 en el Casco Urbano. Las principales actividades económico sociales del municipio son: Sector Agropecuario, Minería $(\mathrm{Au}+\mathrm{Ag}$ ), comercio, servicios e infraestructura. Con una Población Total: 13,799 según el anuario Estadístico 2014. INIDE (Jirón, 2016).

En la primera Unidad de Muestreo objeto de estudio (Microempresa Quesera, Pedro Lazo) se aisló la biota procedente de 6 puntos (Figura 1) distribuidos en 4 condiciones seleccionadas para el proceso (Leche cruda, Suero lácteo, queso y residuos del proceso), obteniéndose un amplio espectro de crecimiento microbiológico en función de los 5 diferentes medios de cultivo empleados para su inoculación (AN, PDA, LB, PCA y $\mathrm{AM}$ ), (Figura 2). La aparición de las primeras poblaciones microbianas requirió menos de 24 horas, obteniéndose aislados como los que se muestran en la Figura 2.

Luego de aislar y purificar durante 10 días las diferentes formas microbianas distinguidas en los cultivos iniciales, se lograron obtener un total de 92 aislados; 76 bacterias, 3 hongos levaduriformes (Figura 3) y 13 aislados de hongos filamentosos, algunos de los cuales se muestran en la Figura 4.

Los registros históricos señalan el uso artesanal de las fermentaciones microbianas para la obtención de alimentos, así como el consumo de microorganismos y el empleo de fuentes portadoras de antibióticos en culturas muy antiguas, por lo que algunos autores consideran que la Biotecnología es una práctica antigua (Wong-Paz et al., 2011). Otros en cambio, no conciben las fermentaciones artesanales como procesos biotecnológicos porque no se sustentan en conocimientos científicos, no se controlan las condiciones de operación ni se utilizan microorganismos seleccionados (García-Garibay et al., 2004). 

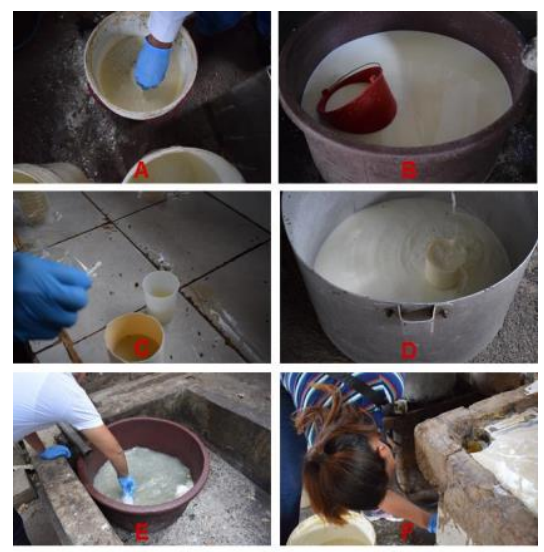

Figura 1. Puntos de Muestreo en Quesera Artesanal Pedro Lazo. (a) I: Suero Simple Fermentado, (b) II: Leche Fresca, (c) III: Salitre, (d) IV: Leche Descremada, (e) V: Agua de Lavado, (f) VI: Muestra de Piso.
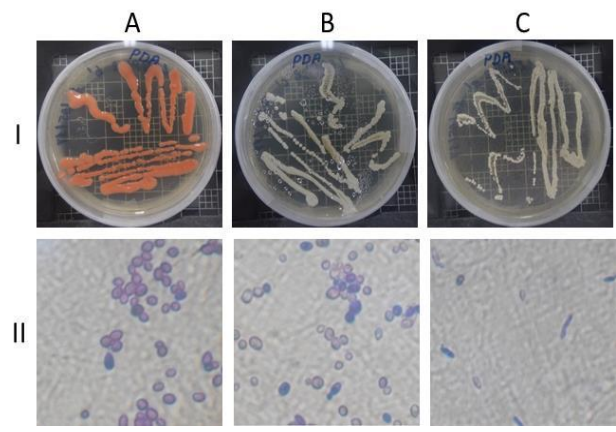

Figura 3. Hongos Levaduriformes Aislados de Quesera Artesanal Pedro Lazo. Se muestra su crecimiento en medio Agar Papa Dextrosa y su respectiva observación de células al microscopio con un objetivo de 50x: AI y AII, BI y BII, CI y CII.

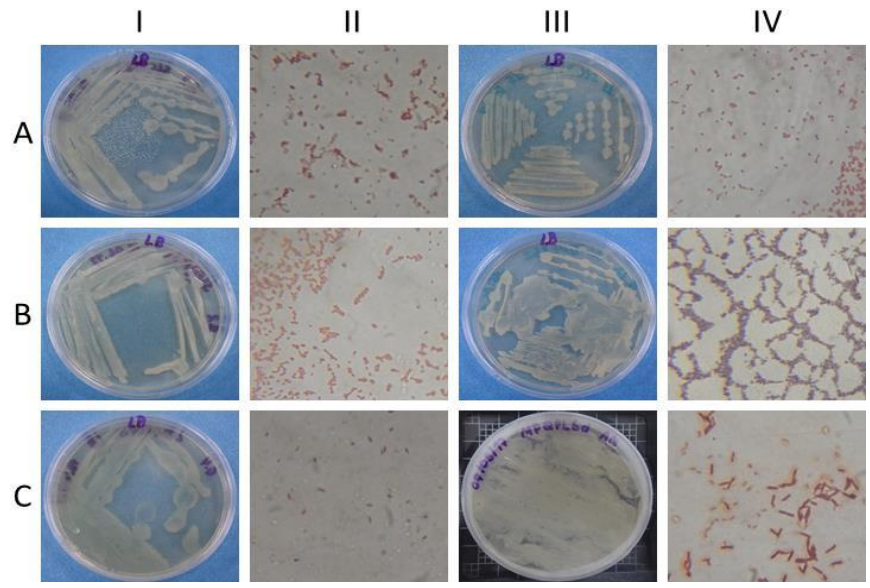

Figura 2: Aislados Bacterianos obtenidos en Quesera Artesanal Pedro Lazo. Se muestra el crecimiento de los aislados en medio de cultivo LB y su respectiva repuesta a la Tinción Gram: CI y CII, BIII y BIV; Gram Positivas y AI y AII, BI y BII, AIII y AIV, CIII y CIV; Gram Negativas.

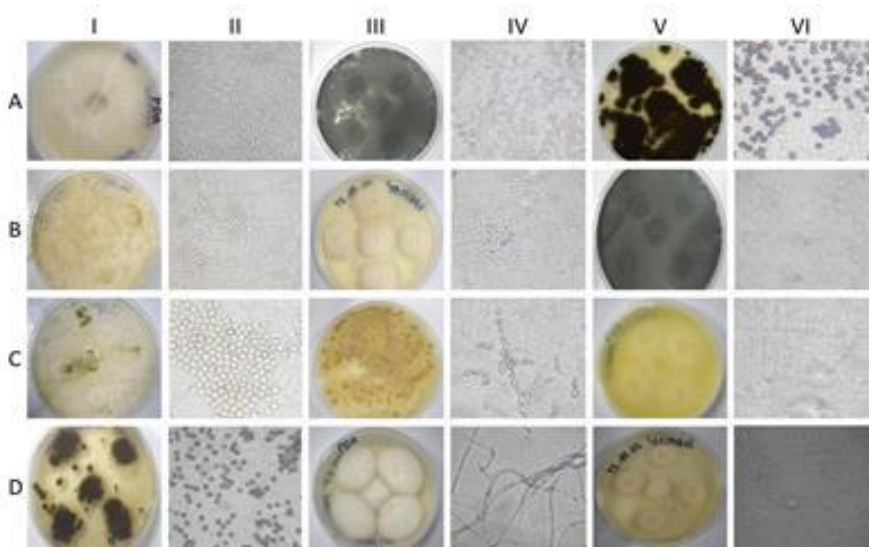

Figura 4. Hongos Filamentosos Aislados de Quesera Artesanal Pedro Lazo. Se muestra su crecimiento en medio Agar Papa Dextrosa y su respectiva observación de esporas al microscopio con un objetivo de 50x: AI y AII, BI y BII, CI y CII, DI y DII, AIII y AIV, BIII y BIV, CIII y CIV, DIII y DIV, AV y AVI, BV y BVI, CV y CVI, DV y DVI.

En Nicaragua, uno de los países centroamericanos con gran biodiversidad, se pueden encontrar temas de investigación como la bioprospección de enzimas de restricción en bacterias de suelos y ambientes volcánicos, recursos valiosos utilizados en varias técnicas de la biología molecular por cuanto se les emplea para cortar el ADN en sitios específicos con aplicaciones en la secuenciación y posterior elaboración de mapas de esta molécula, en el diagnóstico genético, en la tecnología del ADN recombinante y clonación. Entre los beneficios que se podrían obtener se encuentra la comercialización de nuevas enzimas patentables lo que generaría recursos financieros para continuar con los proyectos de Bioprospección, así como también la formación de recursos humanos (Gómez-Rodríguez y Huete-Pérez, 2008). Los subproductos de origen animal también han sido evaluados como sustrato de fermentación para la obtención de bebidas alcohólicas 


\section{L.A. Páramo-Aguilera et al.}

y fermentadas, proteína unicelular, pro bióticos, enzimas, exo polisacáridos y diversos ácidos orgánicos, entre otros (Piñero-Bonilla, 2013).

Como producto del trabajo de bioprospección microbiana realizado en la quesera artesanal de la Libertad Chontales, se obtuvieron 76 aislados bacterianos que se encuentran en fase de identificación final por vía molecular utilizando herramientas de la bioinformática, al igual que los 13 aislados de hongos filamentosos y los 3 levaduriformes. Esta pequeña colección microbiana, una vez identificada, podría ser de gran valor para el desarrollo de diversos procesos biotecnológicos como el desarrollo de procesos para el aprovechamiento del lacto suero desarrollando la producción de bebidas fermentadas, alcohólicas, proteína unicelular entre otras. Por otra parte, Nicaragua posee una amplia producción de quesos para el consumo nacional y para la exportación, pero lamentablemente no producimos los cultivos biológicos que se requieren para la producción del yogurt, la cuajada fresca, la lecha agria o las enzimas que se requieren para el cuajado del queso y la rica cuajada. La producción de pro bióticos, es un campo que se ha explorado por parte de otros grupos de investigación en Nicaragua, pero no se han obtenido mayores avances, debido a la falta de aislados nacionales que puedan utilizarse en dichos procesos. Todo esto nos lleva a afirmar, que los resultados de esta fase del proyecto bioprospección en la quesera artesanal, abre las puertas a un mundo de oportunidades en materia de investigación biotecnológica, que demandará de recursos para el desarrollo de procesos, pero que, en el corto o mediano plazo, podría estar en condiciones de retribuir económicamente al país contribuyendo al desarrollo industrial del mismo.

\subsection{Muestreo en Microempresas mineras de Juan Carlos Chavarría y Aracely Díaz Olivares}

La minería artesanal (MA) se refiere a las actividades informales llevadas a cabo utilizando poca tecnología y maquinaria. Se estima que más de 100 millones de personas realizan estas actividades, especialmente en países en vías de desarrollo. En algunas zonas se generan conflictos debido a que la MA se practica en las proximidades de las minas de gran escala. Actualmente se pueden observar distintas formas de exposición a metales siendo algunas de ellas el agua proveniente de mantos freáticos y los efluentes producidos por algunas actividades industriales como el curtido de pieles, y la minería. Muchos metales, en cantidades traza, tienen un papel integral en los procesos biológicos; sin embargo, algunos de ellos pueden llegar a ser peligrosos para los organismos en concentraciones altas, requiriéndolos así, en cantidades mínimas (Valko et al., 2005).

La actividad minera artesanal en la Libertad, Chontales, se lleva a cabo en la rastra (lugar de trabajo); está en zonas aledañas al pueblo generalmente, estas están al aire libre con techos de plástico o zinc y cerca de una fuente de agua natural o por tubería, siempre hay grandes cantidades de tierra y piedras con bordes afilados en el lugar donde están trabajando, el piso es desnivelado y con algunas zanjas, hay mucho lodo y herramientas por todo el lugar (Figura 5).
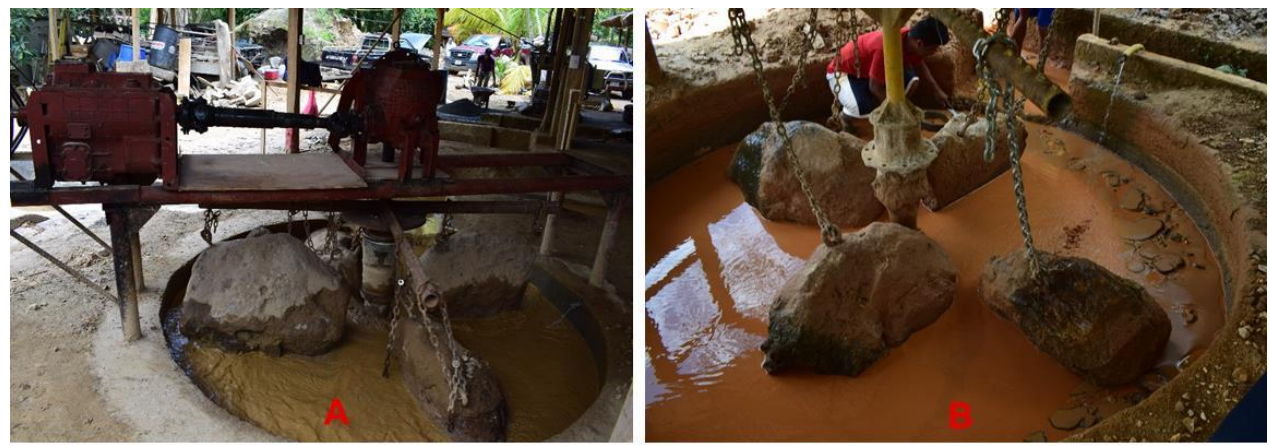

Figura 5. Sito de Muestreo. (A) Minería artesanal de Juan Carlos Chavarría (JCCH), (B) Minería artesanal de Aracely Díaz Olivares (ADO). 


\section{L.A. Páramo-Aguilera et al.}

Para el muestreo de estos sitios se definieron siete puntos (Figura 6), cuatro en la minería artesanal de Juan Carlos Chavarría y tres en la minería de Aracely Díaz Olivares, los cuales se describen a continuación: A. Cola o lama fresca, B. Cola o lama Vieja JCCH, C. Dique de cola, D. Agua de desecho, E. Cola o lama vieja ADO, F. Drenaje de lodos, G. Lodo estancado en drenaje. Algunos de los aislados bacterianos obtenidos y su correspondiente tinción Gram, se muestran en la Figura 7.

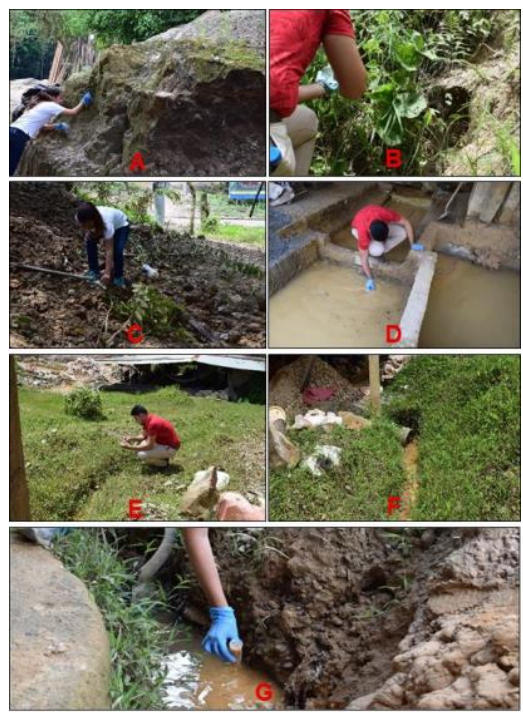

Figura 6. Puntos de Muestreo en Minerías Artesanales. (a) I: Cola fresca, (b) II: Cola Vieja, (c) III: Dique de cola, (d) IV: Agua de desecho, (e) V: Cola vieja, (f) VI: Drenaje de lodos, (g) VII: Lodo estancado en drenaje.
A

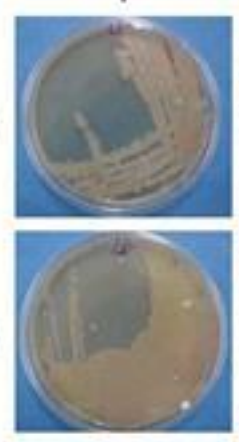

C

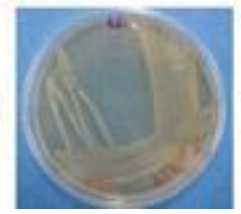

II
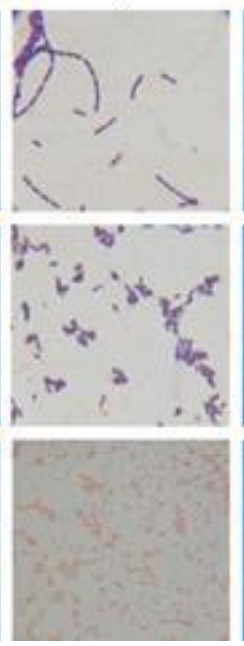
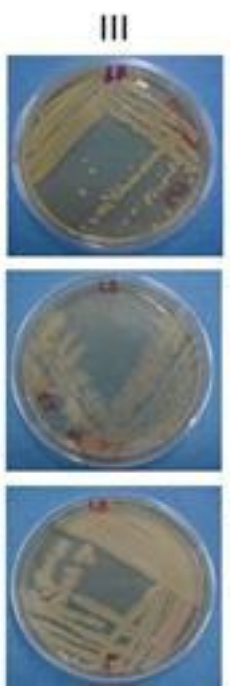
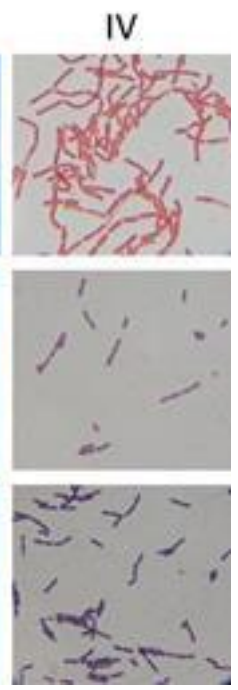

Figura 7. Se muestran algunos aislados Bacterianos obtenidos del Punto I: Cola Fresca perteneciente a la minería de Juan Carlos Chavaría. Se muestra el crecimiento de los aislados en medio de cultivo LB y su respectiva repuesta a la Tinción Gram: AI y AII, BI y BII, BIII y BIV, CIII y CIV; Gram Positivas y CI y CII, AIII y AIV; Gram Negativas.

Del proceso de aislamiento y purificación en minerías artesanales se obtuvieron 68 aislados en total, de los cuales 44 son bacterianos (Figura 7). También se aislaron 6 hongos levaduriformes como los mostrados en la Figura 9 y 18 aislados de hongos filamentosos (Figura 8).

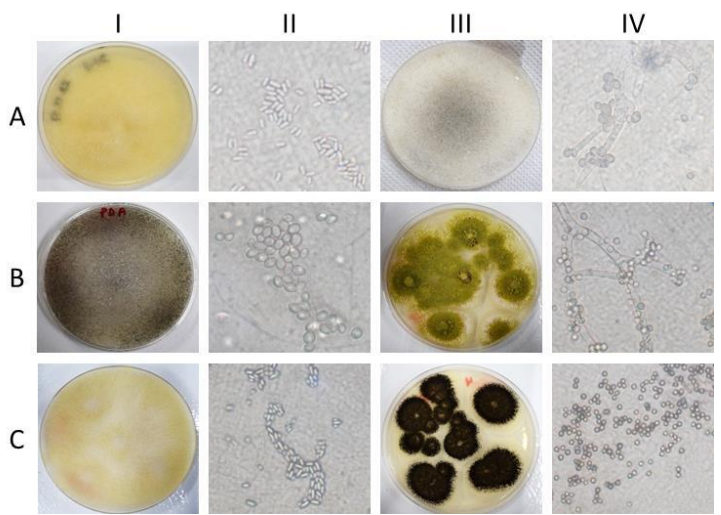

Figura 8. Hongos Filamentosos Aislados de Minerías Artesanales pertenecientes a Juan Carlos Chavarría y Aracely Díaz Olivares; Obtenidos de los siete puntos de muestreos. Se muestra su crecimiento en medio Agar Papa Dextrosa y su respectiva observación de esporas al microscopio con un objetivo de 50x: AI y AII, BI y BII, CI y CII, AIII y AIV, BIII y BIV, CIII y CIV.
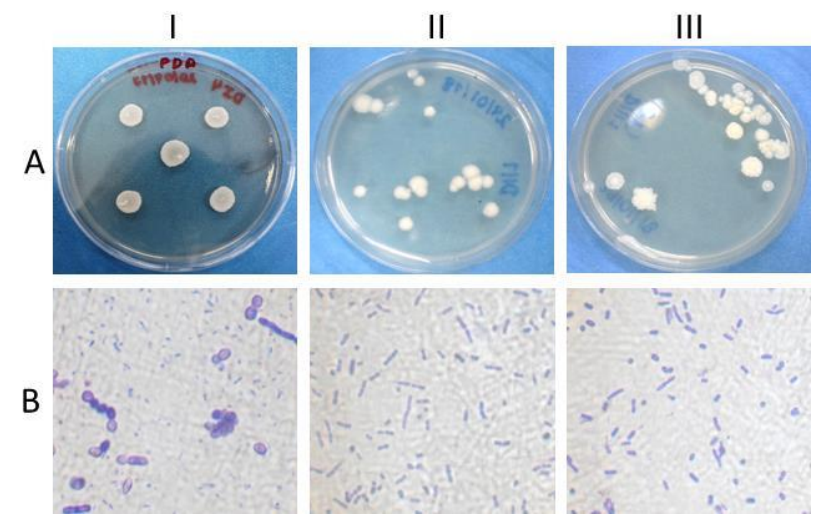

Figura 9: Hongos Levaduriformes Aislados de Minerías Artesanales pertenecientes a Juan Carlos Chavarría y Aracely Díaz Olivares; Obtenidos de siete puntos de muestreos. Se muestra su crecimiento en medio Agar Papa Dextrosa y su respectiva observación de células al microscopio con un objetivo de 50x: AI y BI, AII y BII, AIII y BIII.

Nexo Revista Científica / Vol. 31, No. 02, pp. 89-103 / Diciembre 2018 


\section{L.A. Páramo-Aguilera et al.}

El uso de metales pesados genera la degradación de los ecosistemas edáficos y de los ecosistemas hídricos adyacentes a la zona de explotación, y posiblemente en estos ecosistemas podemos encontrar microorganismos que son capaces de convivir a estas condiciones y que pueden ser usados con fines de bioprospección. Los "desechos mineros" (jales) contienen materiales sólidos potencialmente tóxicos suspendidos en el líquido fluidificado que es descargado en la presa de jales y, al secarse, el material particulado sólido es diseminado por el viento que lo deposita sobre la superficie del suelo y de las aguas superficiales próximas al yacimiento minero. Los lixiviados son otra fuente de contaminación ambiental al arrastrar la fracción soluble de dichos residuos a los mantos freáticos (Lizárraga-Mendiola y col., 2006). Los jales se depositan en barrancas o planicies próximas a la zona de explotación minera, el suelo queda recubierto por capas sucesivas de este material sólido, cuya altura y compactación se incrementa continuamente por las nuevas descargas. Los jales difieren de los suelos en su composición química, que es relativamente uniforme y, sobre todo, que carecen de materia orgánica y otros elementos necesarios para la vida como el nitrógeno y el fósforo. Tienen un contenido de humedad muy limitado, ya que debido a su tamaño de partícula tienen una estructura sólida compacta y prácticamente carente de espacios de aire y de agua. La falta de materia orgánica, agua y aire, son factores que evitan que al interior del material sólido (jal) pueda desarrollarse la microbiota nativa que contribuiría a mantener una superficie fértil en la que pudiera crecer y mantenerse una sucesión de especies vegetales. La siembra de jal (Delfín-Alcalá y Duránde-Bazúa, 2008) en una batería de medios de cultivo líquidos indicó la presencia de biota nativa que a la observación microscópica mostró diversidad de hongos y bacterias, que se identificaron tentativamente a través de bioensayos. A partir de los cultivos mixtos iniciales se aislaron Aspergillus nidulans, Helicosporium panacheum, Humicola alopallonella, Alternaria alternata y Cladobotryum mycophilum. El cultivo en medio de Barr mostró la presencia de bacterias anaerobias sulfatorreductoras, identificadas bibliográficamente como Desulfovibrio desulfuricans.

Los resultados de la bioprospección de la microbiota en las minas artesanales de la Libertad, Chontales; al haberse obtenido hasta un total de 68 aislados; presupone una buena colecta con grandes posibilidades de encontrar diversos microrganismos adaptados a las condiciones ambientales del lugar. Al haberse hecho un muestreo en una serie de puntos con condiciones diversas como se mostró en la Figura 6, permite una captación grande de microorganismos diversos que se muestra en los 18 hongos filamentosos diferentes, los 44 aislados bactarianos y 6 hongos de naturaleza levaduriformes. Es en los diques de colas en donde se dan condiciones similares a los jales descritos por Delfín-Alcalá y Durán-de-Bazúa, 2008; pero la toma de muestras en otros lugares con mayor incidencia de luz, aireación y agua, permiten un mayor crecimiento y captación de la biota nativa. El que estos microorganismos estén habitando estos lugares y una vez que los hayamos identificado, permitirá trabajar en la restauración de estos sitios que hoy están grandemente contaminados tanto por la minería artesanal, como por la industrial y esto traerá mejoras en las condiciones de vida de la población.

\subsection{Muestreo en la Reserva Natural El Chocoyero / El Brujo}

Es una reserva natural que cuenta actualmente con 184 hectáreas de zona protegida, pero con buenas posibilidades de ampliarse para dar una mayor cobertura a la abundante flora y fauna del lugar (Figura 10). Se ubica a unos 28 kilómetros al sur de Managua (Capital de Nicaragua), en el Municipio de Ticuantepe departamento de Managua. La reserva es famosa por sus chocoyos verdes (Loro Verde o Perico del Pacífico), cuyos nidos están cerca de las cataratas. Estos pueden ser vistos en grandes cantidades por las mañanas, cuando alzan el vuelo y se marchan, y por las tardes cuando regresan. Durante el día se pasean por toda la reserva buscando alimento. 


\section{L.A. Páramo-Aguilera et al.}

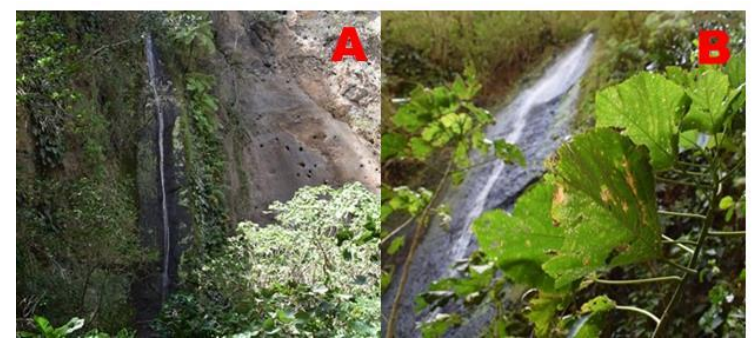

Figura 10. Reserva Natural El Chocoyero / El brujo en el Municipio de Ticuantepe. Departamento de Managua. A. Área de la Cascada del Chocoyero en época seca. B. Área de cascada del Brujo en época seca.

Los microorganismos adaptados a una región determinada pueden preferirse en la selección de aislamientos para el desarrollo de inoculantes destinados a cultivos regionales, ya que podrían ser más competitivos que las bacterias foráneas o introducidas (Karagöz et al.,2012). El desarrollo de biofertilizantes debe iniciarse con el aislamiento de microorganismos de interés y la caracterización de los mecanismos asociados con la promoción del crecimiento vegetal (Vanegas et al., 2011). El interés fundamental al muestrear esta reserva ecológica, consistió fundamentalmente en que, al tratarse de un área de reserva, no está muy intervenida en buena parte por el hombre y sus cultivos agrícolas, así que es muy probable que puedan localizarse microorganismos interesantes para su aplicación en el desarrollo de proceso de producción de biofertilizantes y otros bioinsumos, además de importantes microorganismos desde el punto de vista industrial.

El muestreo de la reserva ecológica El Chocoyero / El Brujo, se llevó a cabo tomando muestras en 9 puntos diferentes que se muestran en la Figura 11. Esto puntos fueron seleccionados sobre la base de considerar la existencia en el lugar de microorganismos degradadores de la materia orgánica que pudiesen tener grandes aplicaciones en la agricultura y la industria. Por otra parte, el hecho de que el lugar este bastante conservado de la contaminación antropogénica, hace suponer la existencia de microorganismos muy útiles en el desarrollo y producción de metabolitos con gran valor industrial.

Como producto del muestreo realizado en la reserva ecológica El Chocoyero / El Brujo, se obtuvo 44 aislados puros. De los cuales 22 son bacterias como las mostradas en la Figura 12 y los otros 22 son hongos filamentosos, algunos de los cuales se muestran en la Figura 13.
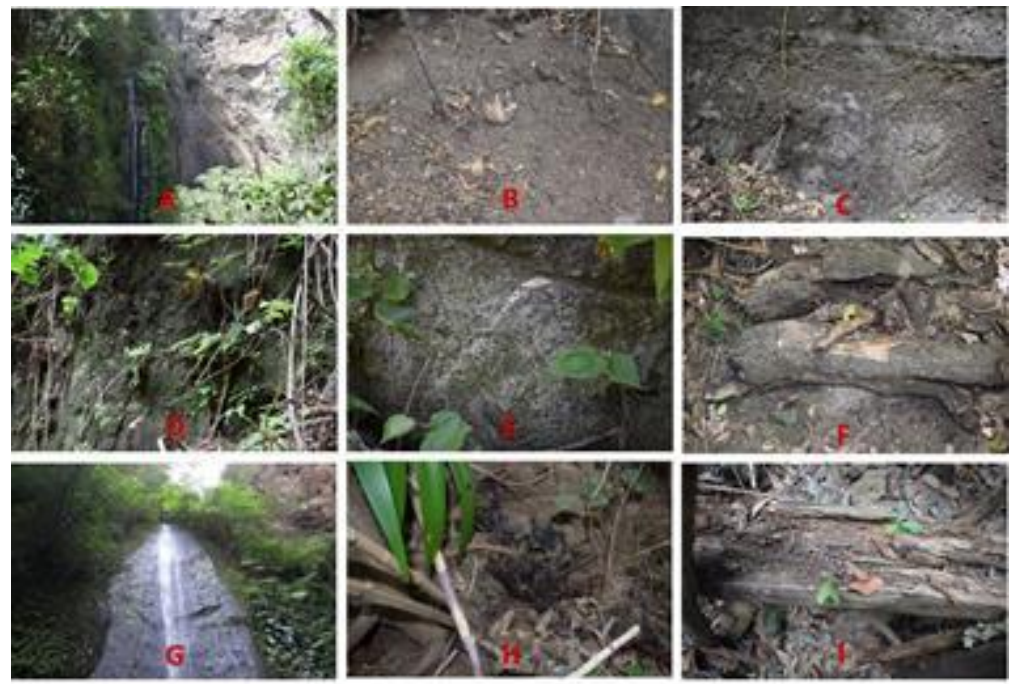

Figura 11: Puntos de Muestreo en Reserva Ecológica El Chocoyero / El Brujo. (A) I: Agua de la cascada, (B) II: Suelo degradado, (C) III: Roca recubierta de biopelícula microbiana blanca, (D) IV: Roca recubierta de lama, (E) V: Roca recubierta de una flora blanca y verdosa, (F) VI: Tronco de un árbol degradado, (G) VII: Agua de la cascada el Brujo (H) VIII: Suelo degradado. (I) IX: Tronco de árbol degradaso.xo Revista Científica / Vol. 31, No. 02, pp. 89-103 / Diciembre 2018 


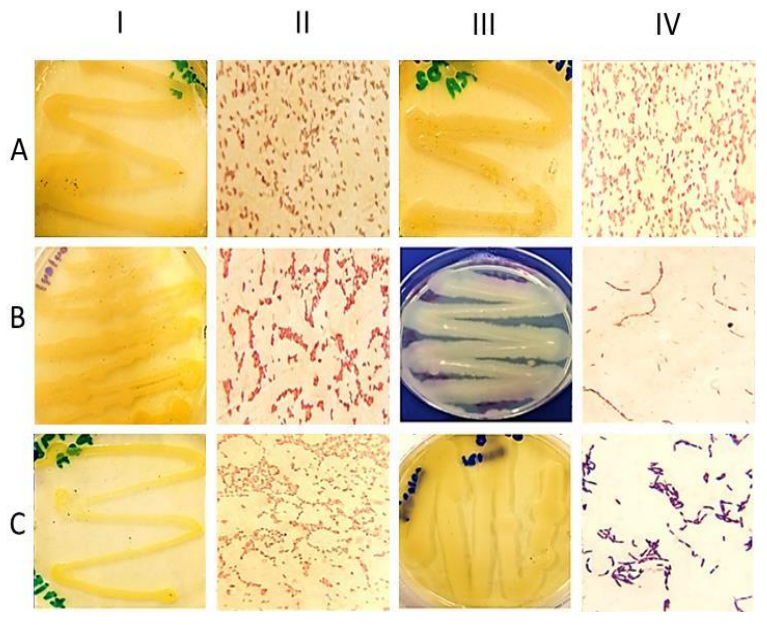

Figura 12. Aislados Bacterianos obtenidos en El Chocoyero / El Brujo. Se muestra el crecimiento de los aislados en medio de cultivo LB y su respectiva repuesta a la Tinción Gram. AI y AII, AIII y AIV, BI y BII, BIII y BIV, CI y CII, CIII y CIV.

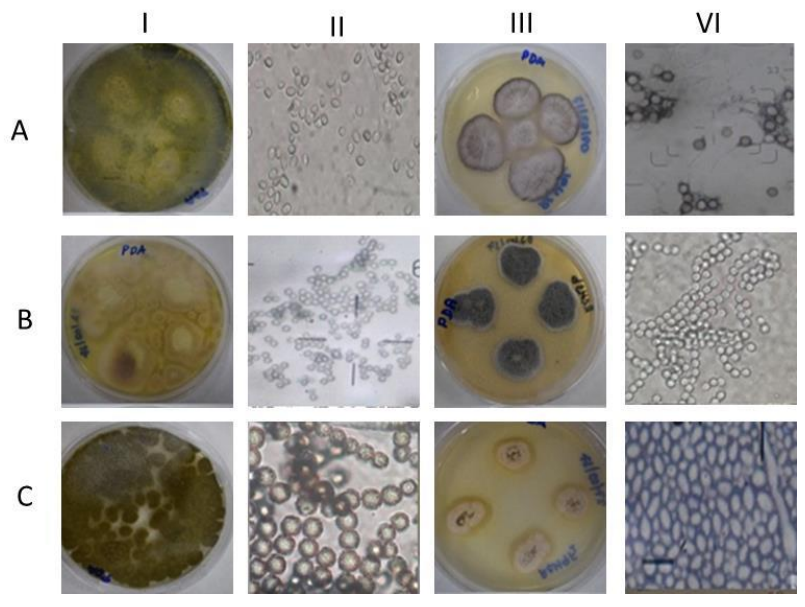

Figura 13. Hongos Filamentosos Aislados de la Reserva Natural Chocoyero / El Brujo. Se observa su crecimiento en medio Agar Papa Dextrosa y sus respectivas esporas al microscopio con un objetivo de 50x. AI y AII, AIII y AIV, BI y BII, BIII y BIV, CI y CII, CIII y CIV.

La bioprospección involucra actividades de investigación, interacciones y procesos para garantizar el mantenimiento in situ y ex situ de los organismos, de las poblaciones naturales y de los ecosistemas sobre los que se ejerce mayor presión, bien sea por causas naturales o antrópicas. En el proceso de aprovechamiento de un recurso natural el bioprospector debe tener en cuenta la forma de aprovechamiento y el conocimiento sobre los organismos a utilizar. Debe asegurar la reposición de los organismos y la conservación de las condiciones del ecosistema que los sustenta; y desarrollar y emplear metodologías que permitan la producción a gran escala y la conservación del recurso natural. Por lo anterior, se observa que la bioprospección es un elemento que subyace a los asuntos relacionados con la diversidad biológica, debido a que no solo hace parte del desarrollo sostenible del potencial económico de la biodiversidad, sino que se encuentra relacionada directamente con el conocer y conservar la biodiversidad (Melgarejo, 2003).

De lo dicho previamente por Melgarejo 2003, se desprende que este trabajo de bioprospección realizado en la reserva ecológica El Chocoyero/El Brujo, tiene una gran importancia para Nicaragua, porque hasta donde se conoce, no existe un trabajo previo realizado en esa área y con este mismo propósito. Por tanto, el conocer alguna parte de la micro biodiversidad existente en ese lugar, nos dará una mejor idea de cómo protegerlo y con qué riquezas contamos en el lugar, a la vez que el desarrollo de procesos con microrganismos provenientes de ahí podría aportar los recursos económicos tan necesarios para la conservación y el desarrollo sostenible del lugar.

\subsection{Rio Chiquito}

La ciudad de León está ubicada a una latitud $12^{\circ} 26.27^{\prime}$ y longitud $86^{\circ} 52.68^{\prime}$. Las empresas se ubican en la zona sur oeste, colinda con los barrios subtiava y laborío y a orillas del rio chiquito. Esta ubicación hace que la contaminación del rio sea notable y un tema importante ya que la población además de contaminarlo con basura y desechos hace uso de sus aguas para diversas labores, lo que conlleva a una cadena de contaminación. La subcuenca Río Chiquito (Figura 14) tiene una expresión municipal y gran parte de la subcuenca lo ocupa el centro urbano del municipio de León por lo que se considera una subcuenca urbana, se ubica en la región del Pacífico de Nicaragua, en el departamento de León, es tributaria de la cuenca No. 64 (Entre Volcán Cosigüina y Río Tamarindo) y drena al Océano Pacífico (Martínez-Cubillo, 2013). 


\section{L.A. Páramo-Aguilera et al.}

Los mataderos se rigen por la necesidad alimenticia y el curtido de pieles es una actividad estrechamente ligada a sectores productivos como la industria del calzado. Estas industrias están fuertemente establecidas en la ciudad de León, Nicaragua, habiendo aproximadamente 3 mataderos y 23 curtidoras (Reconocidas), hay aproximadamente quince teneros trasladados a donde fue construido el Complejo industrial de teneros a doscientos metros de "la Chanchera", carretera a Poneloya y los otros aún se oponen a dejar el lugar donde tradicionalmente han funcionado. Más del $90 \%$ utilizan técnicas artesanales y sin ningún método para tratar sus desechos. El río mide 21 kilómetros de longitud, 17 de ellos en el área rural y 4.5 kilómetros dentro del perímetro urbano, aproximadamente $3 \mathrm{~km}$ cubren las tenerías, atraviesa de norte a sur toda la localidad y es considerado por distintas organizaciones medioambientales como una pequeña reserva natural de flora y fauna en el departamento (Martínez-Cubillo, 2013).

En el muestreo realizado en el Río Chiquito se obtuvo 51 aislados puros, de los cuales 43 son aislados bacterianos y se muestran algunos de ellos en la Figura 15, 7 son hongos filamentosos como los que se muestran en la Figura 16 y 1 es una posible levadura como la mostrada en la Figura 17.

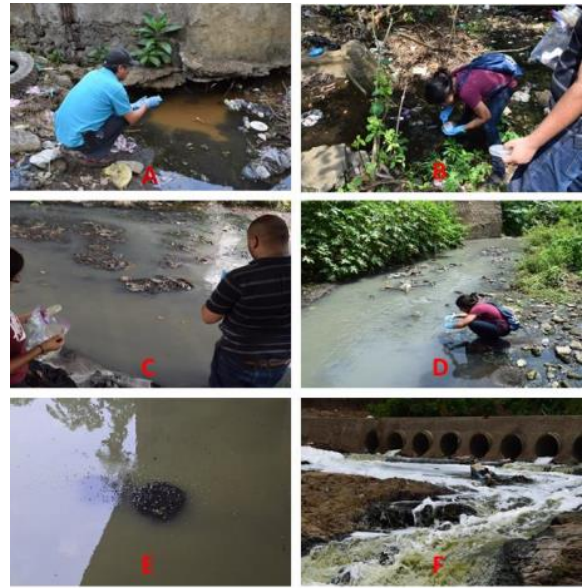

Figura 14. Puntos de Muestreo en el Río Chiquito en donde se tomaron sólo muestras de agua. (a) I: Vertiente del puente bypass, (b) II: Vertiente del puente la vía 23 de Julio. (c) III: Vertiente del puente Martínez El Calvario. (d) IV: Vertiente del puente Tenería Los Leones. (e) V: Vertiente del puente Camino al Fortín Tenerías. (f) VI: Vertiente del puente donde se unen los desagües de pilas sépticas, tenerías, consumo doméstico.
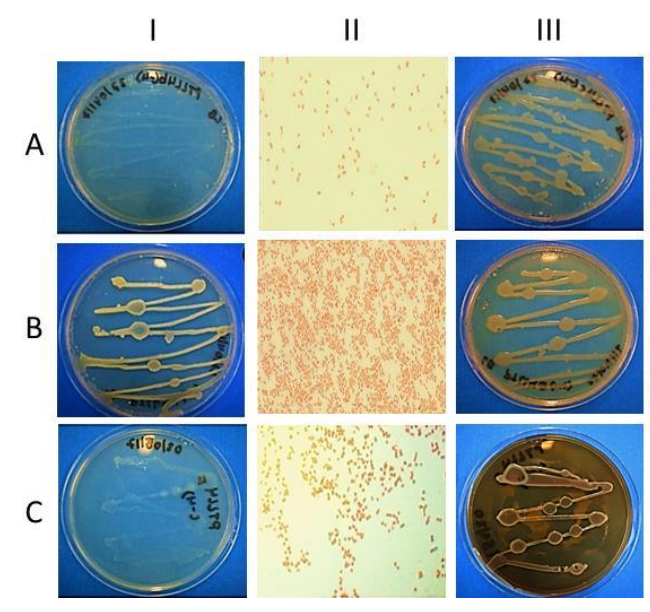

IV

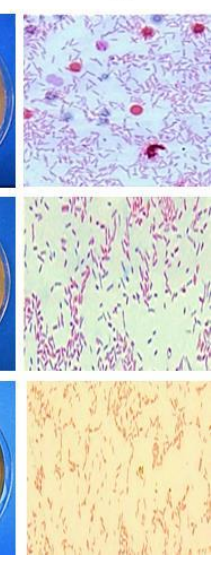

Figura 15. Aislados Bacterianos obtenidos en el Río Chiquito. Se muestra el crecimiento de los aislados en medio de cultivo LB y su respectiva repuesta a la Tinción Gram: AI y AII, AIII y AIV, BI y BII, BIII y BIV, CI y CII, CIII y CIV; obtenidos del punto IV.

Hasta donde hemos podido revisar, en Nicaragua poco o prácticamente nada se ha reportado de estudios de aislamiento e identificación microbiana (En sentido amplio) realizados a muestras de aguas extraídas del Rio Chiquito de la ciudad de León / Nicaragua. Fonseca-Andino y Galeano-Alonzo, 2012, realizaron trabajos de aislamiento microbiano a muestras de aguas tomadas del Rio Chiquito, sin embargo, este trabajo tenía el objetivo específico de búsqueda de Enterococcus spp logrando aislar e identificar por vía morfológica alrededor de 55 aislados los cuales finalmente identificaron como pertenecientes al género Enterococcus. Además del trabajo antes mencionado, no conocemos de la existencia de trabajos previos que hayan realizado una amplia bioprospección en la búsqueda de captar microrganismos habitantes del lugar y que una vez identificados por vía molecular, se les pueda correlacionar con las posibles funciones que ellos hacen en el ambiente en el que viven. Es debido a lo antes dicho que este trabajo, se convierte en pionero al tratar de identificar molecularmente microorganismos que crecen en un ambiente tan contaminado como lo es el Rio Chiquito de León y luego buscar correlaciones de estos microrganismos con los procesos que 


\section{L.A. Páramo-Aguilera et al.}

realizan en el lugar y de esta forma diseñar posteriormente, procesos biotecnológicos que permitan que sean estos mismos microrganismos que siendo aplicados nuevamente en su hábitat en mayores proporciones se encarguen de biorremediar el lugar y devolverlo en un tiempo determinado a sus condiciones originales.

A

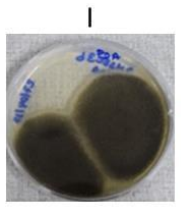

B

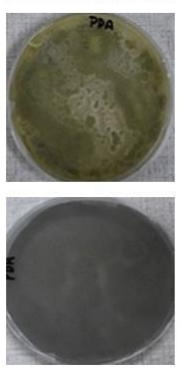

II
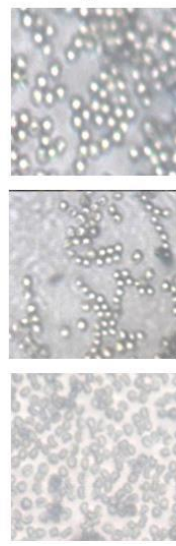
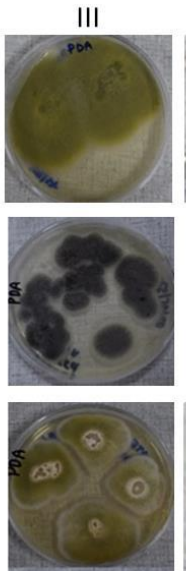

IV

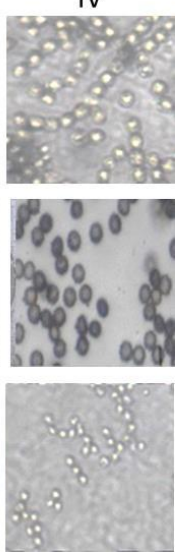

Figura 16. Hongos Filamentosos Aislados de Rio Chiquito; Obtenidos de seis puntos de muestreo todos obtenidos de agua de algunas de las vertientes del rio chiquito en León. Se observa su crecimiento en medio Agar Papa Dextrosa y sus respectivas esporas al microscopio con un objetivo de 50x: AI y AII, AIII y AIV, BI y BII, BIII y BIV, CI y CII, CIII y CIV
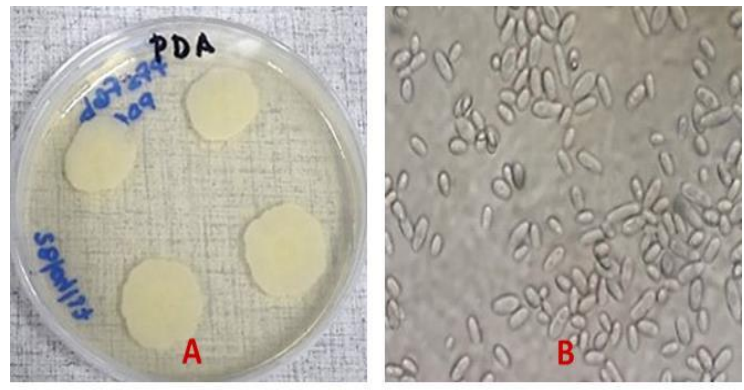

Figura 17: Hongo levaduriforme aislado del punto VI en el Río Chiquito. (A). Crecimiento en medio de cultivo PDA; (B). Vista en microscopio a objetivo 50; (C). Tinción simple o por gota aplastada.

\section{CONCLUSIONES}

Los trabajos de bioprospección microbiana llevados a cabo y que son reportados por medio de estos avances han permitido que a la fecha se cuente con 92 aislados provenientes de la quesera artesanal Pedro lazo (76 bacterias, 3 hongos levaduriformes y 13 aislados de hongos filamentosos). Un total de 68 aislados provenientes de las minas artesanales de La Libertad, Chontales (44 aislados bacterianos, 6 hongos levaduriformes y 18 hogos filamentosos). De la reserva ecológica El Chocoyero / El Brujo, se obtuvieron 44 aislados puros (22 son bacterias y los otros 22 son hongos filamentosos). Finalmente; Del Río Chiquito en la ciudad de León, se obtuvo 51 aislados puros (43 son aislados bacterianos, 7 son hongos filamentosos y 1 es un hongo levaduriforme). Todo esto arroja un gran total de: 255 aislados entre bacterias, hongos filamentosos y levaduriformes, entre los cuales se pueden encontrar muchos con enormes potencialidades biotecnológicas.

La continuidad de los trabajos de identificación microbiana (En los cuales nos encontramos en este momento), nos pondrá como laboratorio en condiciones de poder formular una serie de proyectos de investigación para la búsqueda de financiamiento que permitan el desarrollo de aplicaciones concretas dirigidas a la agricultura, a la industria y al medio ambiente. Ejemplo de lo antes dicho lo constituyen dos proyectos que actualmente estamos en la búsqueda de financiamiento que son: uno dirigido a la continuidad de los trabajos a nivel de invernadero y campo para el desarrollo de un bioinsecticida a base de Bacillus subtilis que fueron aislados e identificados en el laboratorio de biotecnología del PIENSA y otro relacionado con la búsqueda de un sustrato idóneo a nuestras condiciones para la producción masiva de Trichodermas previamente aislados e identificados para ser aplicados en correspondencia con el tipo de cultivo en el que 


\section{L.A. Páramo-Aguilera et al.}

se requiera. A la vez, se trabaja en un proyecto que ya está avanzando y que tiene que ver con el diseño de un consorcio microbiano para la mejora y fertilización de los suelos agrícolas.

\section{AGRADECIMIENTOS}

Los autores desean hacer constar su gratitud al Programa de Investigación Estudios Nacionales y Servicios Ambientales (PIENSA-UNI) y a su directora, la maestra Larisa Korsak; por haber sido contraparte de este proyecto y en cuyas instalaciones se encuentra inmerso el laboratorio de biotecnología en el cual se desarrollan estos trabajos de investigación. Al mismo tiempo desean agradecer a la Universidad Nacional de Ingeniería, quien por medio de su vicerrectoría de Investigación y Desarrollo ha facilitado el aporte financiero para que este proyecto pudiese llevarse a cabo, a todos ellos nuestras mayores muestras de gratitud y compromiso de seguir adelante en la búsqueda de resultados que contribuyan a resolver problemas en las áreas agrícola de la sociedad nicaragüense.

\section{REFERENCIAS}

Bonilla, J. (2013). Importancia biotecnológica de la micro biodiversidad. Los nuevos cazadores de microbios. Revista Venezolana De Ciencia Y Tecnología De Alimentos, 4 (2), 284-317. ISSN: 2218-4384.

Delfín-Alcalá, I y Durán-de-Bazúa, M. Del C. (2008). La microbiota presente en un desecho minero como opción de restauración de Jales. Revista AIDIS de Ingeniería y Ciencias Ambientales: Investigación, desarrollo y práctica. 1 (4), 1-10. ISSN 0718-378XPP.

Fonseca-Andino, M.K y Galeano-Alonzo, G.M. (2012). Fenotipificación bioquímica y susceptibilidad antibacteriana en Enterococcus spp aislados de aguas residuales de León, Junio - septiembre 2012.Trabajo de Tesis para optar al título de Licenciatura en Bio análisis Clínico. Universidad Nacional Autónoma de Nicaragua, León. Facultad de Ciencias Médicas. Carrera Bio análisis Clínico.

Galeano, R.J.P. (2009). El caso Recursos biológicos y genéticos y de propiedad intelectual El debate Biopiratería versus Bioprospección. Revista Republicana. 7, 127-151, ISSN. 1909-445.

García-Garibay, M.; Quintero-Ramírez, R y López-Munguía, C. A. (2004). Biotecnología alimentaria. Editorial Limusa, 13-24. México, D. F., México, S. A. de C. V. Grupo Noriega Editores.

Gómez-Rodríguez, J. A. y Huete-Pérez, J. A. (2008). Bioprospección de enzimas de restricción en bacterias de suelos y ambientes volcánicos de Nicaragua. Revista Encuentro. Año XL, 81, 70-87.

Hazen, T.C., Rocha A.M and Techtmann, S.M. (2013). Advances in monitoring environmental microbes. Current Opinion in Biotechnology, 24, 526-533.

Huete-Perez, J.A. (2008). Biotecnología para el desarrollo de naciones pequeñas. Revista encuentro. Año XL, 79, 89-95.

Jirón, M.L.R. (2016). Características de las condiciones laborales en mineros artesanales, La Libertad, Chontales, Nicaragua, abril, 2016. Informe final de tesis para optar al título de Master en seguridad ocupacional. Universidad Nacional Autónoma de Nicaragua, UNAN. Managua. Centro de Investigación y Estudios de la Salud, Escuela de Salud Pública, Maestría en Salud Ocupacional 2014-2016. 


\section{L.A. Páramo-Aguilera et al.}

Karagöz, K., F. Ates, H., Karagöz, R. K., and R. Çakmakç. 2012. Characterization of plant growthpromoting traits of bacteria isolated from the rhizosphere of grapevine grown in alkaline and acidic soils. Eur. J. Soil Biol. 50, 144-150.

Lezama-Cervantes, C., Paniagua-Michel, J., y Zamora-Castro, J. (2010). Biorremediación de los efluentes de cultivo del camarón Litopenaus vannamei (Boone, 1931) utilizando tapetes microbianos en un sistema de recirculación. Lat. Am. J. Aquat. Res. 38 (1), 129-142.

Lizárraga-Mendiola, L.G., González-Sandoval, M.R., Pacheco-Gutiérrez, L.A., Durán-Domínguez, M.C. (2006). Hidrogeoquímica en una presa de jales en el Estado de México, México. XI Congreso Geológico Chileno. Agosto 7-11, 2006. Antofagasta, Chile.

Martínez-Alonso, M. y Gaju, N. (2005). El papel de los tapetes microbianos en la biorrecuperación de zonas litorales sometidas a la contaminación por vertidos de petróleo. Revista Científica Y Técnica de Ecología Y Medio Ambiente, Ecosistemas. 2 (14), 79-91. ISBN 1697-2473.

Martínez-Cubillo, F.J. 2013. Identificación de contaminantes, prevención y aprovechamiento de desechos orgánicos en la producción de biogás y biodiesel, en curtidoras y mataderos de la ciudad de León, ubicadas en la ladera del Rio Chiquito, septiembre 2012-junio 2013. Tesis para optar al grado de Master en Energías Renovables y medio ambiente. Universidad Nacional Autónoma de Nicaragua, León. Facultad de Ciencias y Tecnología.

Melgarejo, L.M. (2003). Bioprospección: Plan nacional y aproximación al estado actual en Colombia. Acta Biológica Colombiana, 8 (2). 73-86.

Páramo-Aguilera, L.; Narváez-Zapata, J y De la Cruz, E. (2011). Aislamiento e identificación de microorganismos de biopelículas procedentes del Castillo Chapultepec de la ciudad de México. Nexo, 24 (2) 83-91.

Páramo-Aguilera, L. (2012a). Caracterizaciones de comunidades microbianas con potencial biotecnológico para la prevención del deterioro estructural. Tesis de grado para optar al título de Doctor en Ciencias de la biotecnología presentada ante el IPN, CBG, Reynosa, Tamaulipas, México.

Páramo-Aguilera, L.; Ortega-Morales, B.J and Narváez-Zapata, J. (2012b). Culturable fungi associated with urban stone surfaces in Mexico City. Electron. J. Biotechnol. 15 (4), 1-17. ISSN: 0717-3458.

Peña, B y Reyes, I. (2007). Aislamiento y evaluación de bacterias fijadoras de nitrógeno y disolventes de fosfatos en la promoción del crecimiento de la lechuga (Lactuca sativa L.). Interciencia, 32 (8), 560-565. Caracas, Venezuela. ISSN 0378-1844.

Piñero-Bonilla, J. (2013). Importancia Biotecnológica de la micro biodiversidad. Los nuevos cazadores de microbios. Revista Venezolana de Ciencia y Tecnología de Alimentos. 2, (4), 284-317. Julio-diciembre, 2013. ISSN:2218-4384.

Valko, M., Morris, H., and Cronin, M. T. D. (2005). Metals, Toxicity and Oxidative Stress. Current Medicinal Chemistry. 12 (10), 1161-1208.

Vanegas, J., N. Florez-Zapata, y D. Uribe-Vélez. (2011). Bioprospección de microorganismos promotores de crecimiento vegetal para su aplicación en el cultivo de arroz. Editores: Uribe, D., y L. M. Melgarejo (eds). Ecología de Microorganismos Rizosféricos Asociados a Cultivos de Arroz de Tolima y Meta. Bogotá, D. C: Universidad Nacional de Colombia. 151-178. 


\section{L.A. Páramo-Aguilera et al.}

Wong-Paz, J. E.; de la Cruz-Quiroz, R.; Reyes-Arreozola, M. I.; Loredo-Treviño, A. y Aguilar, C. (2011). El pasado de la tecnología e ingeniería biológica. Acta Química Mexicana. Revista Científica de la Universidad Autónoma de Coahuila. 3 (6), 1-7.

\section{SEMBLANZA DE LOS AUTORES}

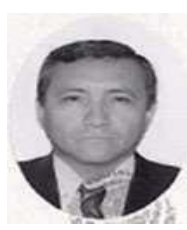

Leandro Alberto Páramo Aguilera, Graduado como Ingeniero Químico con maestría en Ingeniería Química y énfasis en procesos biotecnológicos, en el Instituto Superior Politécnico "José Antonio Echeverría", ISPJAE, de la Ciudad de la Habana, Cuba, en el año 1990. En 1997 se gradúa como Master en Microbiología y énfasis en bacteriología en la Universidad de Costa Rica, UCR. En junio del 2012, se gradúa como Doctor en Ciencias en el área de Biotecnología en el Centro de Biotecnología Genómica (CBG) del Instituto Politécnico Nacional (IPN) de México. Amplia experiencia en el desarrollo de procesos biotecnológicos (biofertilizantes, bebidas alcohólicas, fermentados lácteos, bioprospección, compostaje, etc).

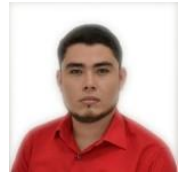

Erick J. Fonseca-Cruz: Estudiante egresado de Ingeniería Química, Miembro de la Excelencia Académica y Monitor de las Asignaturas de Termodinámica Química y Mecánica de Fluidos de la Facultad de Ingeniería Química en la Universidad Nacional de Ingeniería (UNI). Ganador de la Feria de Alimento y Ambiente. Desarrolla trabajos de investigación de carácter innovador a nivel nacional concernientes a la biotecnología dirigido al desarrollo de procesos agroindustriales y participa en talleres de nuevas técnicas de investigación.

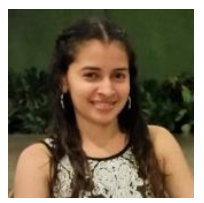

Heysell D. Delgado-Silva: Egresada de Ingeniería Química en la Universidad Nacional de Ingeniería (UNI)). Curso Ingles Básico y Cultura Emprendedora y cursa Técnico General en Contabilidad en el Instituto Nacional Técnico para la Administración y Economía. Desarrolla proyecto de investigación en el Programa de Investigación Estudios Nacionales y Servicios de Ambiente (PIENSA), con interés en el área de biotecnología para el desarrollo de procesos industriales y agrícolas. Ha participado en varios congresos nacionales y latinoamericano en diversas áreas; XXII Congreso Latinoamericano de Estudiantes de Ingeniería.

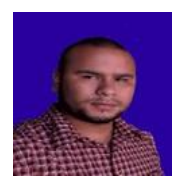

Kevin E. Cabistán-Calderón: Es egresado de la Facultad de Ingeniería Química de la Universidad Nacional de Ingeniería con mención en ingeniería ambiental. Desarrolla trabajos de investigación de carácter innovador a nivel nacional concernientes a la biotecnología dirigido al desarrollo de procesos medio ambientales y participa en talleres de nuevas técnicas de investigación.

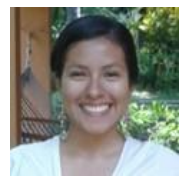

Cesia K. Ríos-Guevara: Estudiante egresada de Ingeniería Química de la Universidad Nacional de Ingeniería (UNI). Desarrolla trabajos de investigación de carácter innovador a nivel nacional concernientes a la biotecnología dirigido al desarrollo de procesos medio ambientales y participa en talleres de nuevas técnicas de investigación. 